International Journal of Medical Sciences

ISSN 1449-1907 www.medsci.org 2008 5(6):313-318

Review

(C) Ivyspring International Publisher. All rights reserved

\title{
The treatment of condylar fractures: to open or not to open? A critical review of this controversy
}

\section{Renato VALIATI 1*, Danilo IBRAHIM ${ }^{* *}$, Marcelo Emir Requia ABREU1*, Claiton HEITZ2*, Rogério Belle de OLIVEIRA ${ }^{2 *}$, Rogério Miranda PAGNONCELLI ${ }^{\star}$, Daniela Nascimento SILVA ${ }^{2 \star} \bowtie$}

1. School of Dentistry, Pontifícia Universidade Católica do Rio Grande do Sul (PUCRS), Porto Alegre, Brazil.

2. Post-Graduation in Dentistry - Department of Surgery (Head: Prof. Dr. José Antônio Poli Figueiredo) - Pontifícia Universidade Católica do Rio Grande do Sul (PUCRS), Porto Alegre, RS, Brazil.

* These authors contributed equally.

$\triangle$ Correspondence to: Daniela Nascimento Silva, MSc, PhD, School of Dentistry - PUCRS - Av. Ipiranga, 6681, Prédio 6, Sala 209, CEP 90619-900 - Porto Alegre, RS - Brazil. danitxf@hotmail.com, Telephone/Fax: +55 (51) 3320-3538.

Received: 2008.10.01; Accepted: 2008.10.22; Published: 2008.10.23

The treatment of condylar process fractures has generated a great deal of discussion and controversy in oral and maxillofacial trauma and there are many different methods to treat this injury. For each type of condylar fracture, the techniques must be chosen taking into consideration the presence of teeth, fracture height, patient's adaptation, patient's masticatory system, disturbance of occlusal function, deviation of the mandible, internal derangements of the temporomandibular Joint (TMJ) and ankylosis of the joint with resultant inability to move the jaw, all of which are sequelae of this injury. Many surgeons seem to favor closed treatment with maxillomandibular fixation (MMF), but in recent years, open treatment of condylar fractures with rigid internal fixation (RIF) has become more common. The objective of this review was to evaluate the main variables that determine the choice of method for treatment of condylar fractures: open or closed, pointing out their indications, contra-indications, advantages and disadvantages.

Key words: mandibular condyle; temporomandibular joint; mandibular fractures; internal fracture fixation; jaw fixation techniques.

\section{INTRODUCTION AND LITERATURE REVIEW}

Mandibular fractures are extremely frequent in facial trauma, and $19-52 \%$ involve the condyle. Condylar fractures are classified according to the anatomic location (intracapsular and extracapsular) and degree of dislocation of the articular head.1-9

The complications of condylar fracture include pain, restricted mandibular movement, muscle spasm and deviation of the mandible, malocclusion, and pathological changes in the TMJ, osteonecrosis, facial asymmetry, and ankylosis, irrespective of whether treatment was performed or not.2,4,10 They also include fracture of the tympanic plate, mandibular fossa of temporal bone fracture, with or without displacement of the condylar segment into the middle cranial fossa, damage to cranial nerves, vascular injury, bleeding, growth disturbance, arteriovenous fistula, ${ }^{11}$ and alter the balance in the masticatory muscles. ${ }^{12}$

Since the introduction of osteosynthesis materials for rigid internal fixation after anatomical reduction there has been ongoing discussion about the treatment of condylar fractures of the mandible. ${ }^{13}$ There are two principal therapeutic approaches to these fractures: functional and surgical. ${ }^{3}$

In recent years, open treatment of condylar fractures has become more common, probably because of the introduction of plate and screw fixation devices that allow stabilization of these injuries. Nevertheless, several reports and a few series of open treatments have emerged in the world literature., ${ }^{4,5,14}$

Intracapsular fractures of the mandibular condyle are classified as type A, fractures through the medial condylar pole; type B, fractures through the lateral condylar pole with loss of vertical height of the mandibular ramus; or type $\mathrm{M}$, multiple fragments, comminuted fractures. The majority of mandibular condyle fractures involve the condylar neck, with few reports of intracapsular fractures. Sagittal or vertical fractures of the mandibular condyle and chip fractures of the medial part of the condylar head are rarely 
found by conventional radiography and are more commonly detected by computed tomography (CT) scan. ${ }^{10}$

For moderately displaced condylar fractures, closed treatment with rigid or elastic maxillomandibular fixation is still frequently selected. The reasons for this may be the difficult surgical access to the condylar area and the frequently difficult repositioning of the proximal fragment. ${ }^{15}$ Open reduction and internal fixation of condylar fractures may be indicated for bilateral injuries or considerably displaced condylar fractures, but closed treatment and intermaxillary fixation (IMF) may be indicated in cases where condylar displacement is minimal and the height of the ramus is almost normal. ${ }^{16}$

Functional therapy (closed treatment) is adopted most frequently, since it permits early mobilization and adequate functional stimulation of condylar growth (in growing subjects) and bone remodeling (in all subjects). It is indicated in almost all condylar fractures that occur in childhood, and in intracapsular and extracapsular fractures that do not include serious condylar dislocation in adults. In contrast, surgical treatment is indicated primarily for adults with displaced fractures or with dislocation of the condylar head. $3,5,17,18$

TABLE 1: Indications for open reduction and rigid internal fixation of mandibular condyle fractures (MITCHELL, $1997^{1}$; HAUG and ASSAEL, $2001^{19}$; BRANDT and HAUG, 2003 ${ }^{30}$ ).

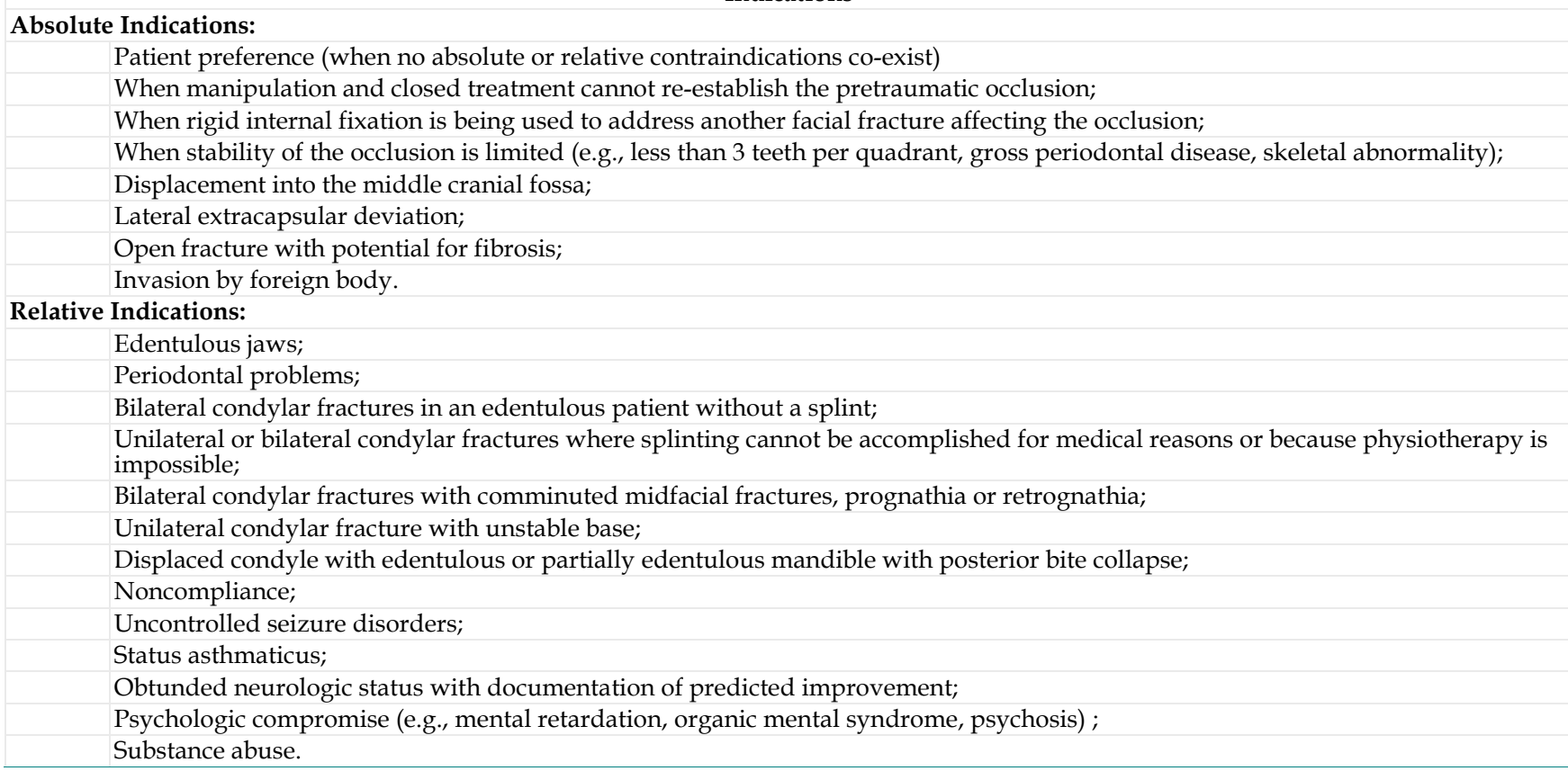

TABLE 2: Contraindications to open reduction and rigid internal fixation of mandibular condyle fractures (MITCHELL, 1997 ${ }^{1}$; HAUG and ASSAEL, $2001^{19}$; BRANDT and HAUG, $2003^{30}$ ).

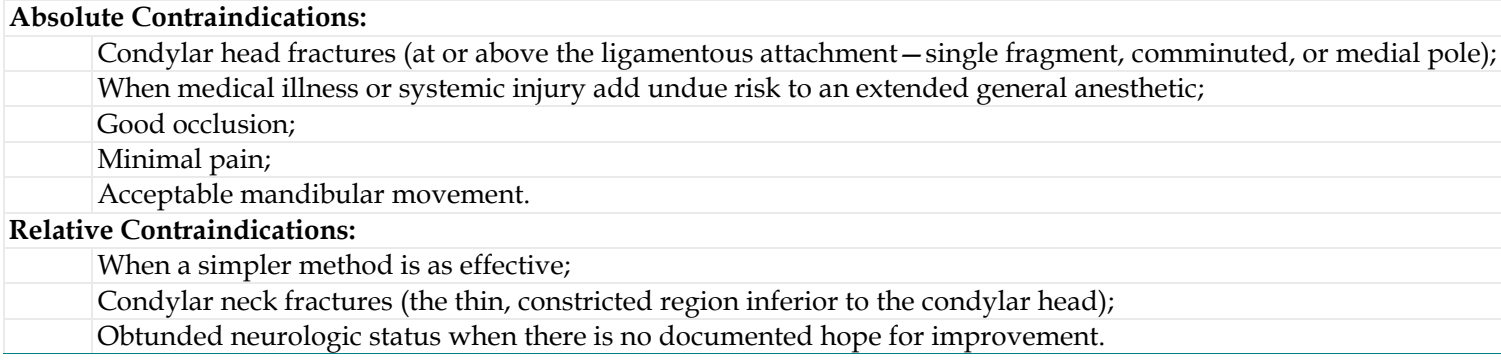

Haug and Assael ${ }^{19}$ compared results of 10 patients treated with closed treatment with maxillomandibular fixation (CRMMF) and 10 treated by open reduction with internal fixation (ORIF) that were recalled after a minimum of 6 months and examined for gender, race, diagnosis, age at injury, 
time since operation, and cause of the fracture. The results showed no statistically significant differences between the ORIF and CRMMF groups for gender, race, diagnosis, or cause. Moreover, there were no differences for age at injury, maximum interincisal opening, right lateral excursion, left lateral excursion, protrusive movement, deviation on opening, or occlusion. Differences were noted between groups for time since operation, scar perception, and perception of pain. The ORIF group was associated with perceptible scars. The CRMMF group was associated with chronic pain. When using a treatment protocol, there were few differences in outcomes between patients treated with CRMMF and ORIF for subcondylar fractures.

Ellis and Throckmorton ${ }^{20}$ compared vertical measures of mandibular and facial morphology after open or closed treatment for fractures of the mandibular condylar process, in one hundred forty-six patients, 81 treated by closed and 65 by open methods. Towne's and panoramic radiographs, taken at several intervals, were used to quantify the displacement of the condylar process fractures. The patients whose condylar process fractures were treated by closed methods had significantly shorter posterior facial and ramus heights on the side of injury, and more tilting of the occlusal and bigonial planes toward the fractured side, than patients whose fractures were treated by open methods. Most of the asymmetry in patients treated by closed methods was present by 6 weeks after injury. The patients treated by closed methods developed asymmetries characterized by shortening of the face on the side of injury. It is likely that loss of posterior facial height on the side of fracture in these patients is an adaptation that helps reestablish a new temporomandibular joint.

In the study of the Santler et al. ${ }^{21}$ two hundred thirty-four patients with fractures of the mandibular condylar process were treated by open or closed methods. In the follow-up study, 150 patients with a mean follow-up time of 2.5 years were analyzed using radiologic and objective and subjective clinical examinations. No significant difference in mobility, joint problems, occlusion, muscle pain, or nerve disorders were observed when the surgically and nonsurgically treated patients were compared. The only significant difference was in subjective discomfort. Surgically treated patients showed significantly more weather sensitivity and pain on maximum mouth opening. Because of these disadvantages, open surgery is only indicated in patients with severely dislocated condylar process fractures.

The study of Marker et al.22 was designed to record the results of closed treatment of condylar fractures and to find out whether there were any variables that were predictive of complications. The ability to open the mouth, deviation and occlusion were recorded. After one year 45 of the 348 patients (13\%) had minor physical complaints such as reduced ability to open the mouth, deviation, or dysfunction. Ten of them $(3 \%)$ had pain in the joint or muscles or both. Eight patients $(2 \%)$ had malocclusion, which in seven could be related to dislocation of the condylar head out of the fossa. Five of the eight patients had had bilateral fractures. They concluded that closed treatment of condylar fractures is non-traumatic, safe, and reliable and in only a few cases may cause disturbances of function and malocclusion.

Sixty-one patients treated by open reduction and internal fixation for unilateral condylar process fractures were studied prospectively to Ellis, Throckmorton and Palmieri ${ }^{23}$ using Towne's and panoramic radiographs. The images were traced and digitized, and the position of the fractured condylar process was statistically compared with the position of the nonfractured condylar process in both the coronal and sagittal planes. After surgery, the difference in position between the fractured and nonfractured sides averaged less than $2^{\circ}$ (not significantly different), indicating good reduction of the fractures. However, subsequently, between $10 \%$ and $20 \%$ of condylar processes had postsurgical changes in position of more than $10^{\circ}$. This study showed that it is possible to anatomically reduce the fractured condylar process, but changes in position of the condylar fragment may then result from a loss of fixation.

Rutges et al. ${ }^{13}$ conducted a study with closed treatment that consisted of maxillomandibular fixation (MMF) with wires if there were severe occlusal disturbances. Mild occlusal disturbances were treated with elastic MMF. If there was no occlusal disturbance, a soft diet was advised. Sixty patient files were analyzed and 28 patients were seen for re-examination and an $\mathrm{X}$ orthopantomogram was taken. Functionality was graded with the Helkimo index at an average of 3.0 years follow-up. The clinical dysfunction index showed: severe symptoms in $11 \%$, moderate symptoms in $39 \%$, mild symptoms in $39 \%$ and $11 \%$ had no symptoms. Index for occlusal state showed: $21 \%$ severe occlusal disturbances, $61 \%$ moderate occlusal disturbances and $18 \%$ no occlusal disturbances. According to the anamnestic dysfunction index $89 \%$ of the patients were symptom-free. The clinical outcome group showed a significant left/right ramus length difference compared with a 20-person control group. The re-examined group did not significantly differ from the control group. 
With the objective of analyzing the main variables that determine the choice of the method of treatment and the outcome in condylar fractures, Villarreal et al. ${ }^{24}$ conducted a retrospective analysis of 104 mandibular condyle fractures to analyze and determine the relationship between the principal clinical variables and the postoperative results. All patients underwent a clinic-radiologic investigation focusing on fracture remodeling, development, dental occlusion, and symmetry of the mandible. They analyzed the influence of the preoperative clinical variables (level of fracture, treatment, postoperative physical therapy, displacement and dislocation, comminution, loss of ramus height, patient age, gender, etiology, occlusion, status of dentition, and presence of facial and mandibular fractures) on the postoperative results and outcome. The principal factors that determined the treatment decision were the level of the fracture and the degree of displacement. The level of the fracture influenced the degree of preoperative coronal and sagittal displacement (neck fractures had greater medial and anterior displacement than head and subcondylar fractures) and the treatment applied. The functional improvement obtained by open methods was greater than that obtained by closed treatment. Open treatment increased the incidence of postoperative condylar deformities and mandibular asymmetry. The variables that influenced the method of treatment and predicted the prognosis were the level of fracture, degree and direction of displacement of the fractured segments, age, medical status of the patient, concomitant injuries, and status of dentition.

To compare the occlusal relationships after open or closed treatment for fractures of the mandibular condylar process, a total of 137 patients with unilateral fractures of the mandibular condylar process (neck or subcondylar), 77 treated closed and 65 treated open, were included in the study of Ellis, Simon and Throckmorton. ${ }^{25}$ Standardized occlusal photographs obtained at several postsurgical time intervals were examined and scored by a surgeon and an orthodontist. The patients treated by closed techniques had a significantly greater percentage of malocclusion compared with patients treated by open reduction, in spite of the initial displacement of the fractures being greater in patients treated by open reduction.

\section{DISCUSSION}

There is consensus in the world literature as regards the treatment of both intercapsular and extracapsular condylar fractures in children, which must be with closed treatment. When this type of opinion was challenged, some authors now admitted the possibility of using open reduction in cases of condylar fractures in children, provided that the technique was minimally invasive, as for example, by endoscopic surgery. ${ }^{26}$ Open reduction in children has recently been more accepted, mainly due to the development, confidence and greater experience of professionals with internal rigid fixation materials. ${ }^{5}$ Nevertheless, there is no consensus as regards the treatment of condylar fractures in adults. Among themselves, the authors agree that in adults, the type of treatment must mainly be chosen on a case by case basis and the personal experience of each professional.1,3,4,8,27-29 There are 3 main treatments advocated for adults with condylar process fractures: 1) a period of maxillomandibular fixation (MMF) followed by functional therapy; 2) functional therapy without a period of MMF; and, 3) open reduction with or without internal fixation. ${ }^{4}$ Basic and very important requirements must be taken into consideration before the choice or option is made for the type of treatment in adult patients, such as: height and quantity of the fracture traces; uni- or bilateral fractures; total or partial loss of teeth; influence of the affected TMJ(s) on mandibular movements and the masticatory system; degree and direction of dislocation of the condyles; difficulty of surgical access; risk of lesion in critical anatomic structures; risk of hypertrophic and/or cheloid scar; patient's general health status; presence of other maxillofacial fractures; possibility of performing physical therapy; neuromuscular adaptations. 2,3,11,24

The absolute indications for open treatment of condylar fractures are in cases of bilateral fractures, $16,27,29$ considerable dislocations, 3,6,16,18,21,24,29 when closed treatment does not re-establish occlusion, $, 1,19,30$ concomitant fractures of other areas of the face that compromise occlusion and for which rigid internal fixation will be used, ${ }^{19}$ foreign bodies such as firearm projectiles and dislocation of the condyle to the middle cranial fossa. 1,30

Some of the complications reported as regards open treatment of condylar fractures are the difficulty of surgical access, ${ }^{14,15}$ extra-oral scars, $14,19,31,32$ lesion of the facial nerve, ${ }^{4,14,31,32}$ plate fracture ${ }^{32,14}$ and aseptic necrosis of the condylar segment secondary to loss of periostal blood supply during dissection for exposure. ${ }^{31}$

The blood supply has been discussed a great deal, because authors argue that surgical access to the condylar process to perform open reduction and internal fixation requires exposure and dissection of some of the soft tissues of the condylar process to allow manipulation and attachment of fixation devices. Therefore, surgery further diminishes the blood supply to a segment of bone that has already been 
severely compromised. If it is important to maintain the blood supply to the condyle, one should choose a surgical approach that can minimize the amount of soft tissue stripping from the fractured condylar process and retain attachment of the TMJ capsule and the lateral pterygoid muscle as far as possible. ${ }^{4,5}$

Treatment of the condyle with closed treatment in adults is indicated in cases of minimum and high dislocations, ${ }^{16,31}$ fractures of the head of the condyle (intracapsular), $19,31,33$ and systemic risks of submitting the patient to general surgery. ${ }^{19}$ According to Marker et al.22 It is a non traumatic, safer and more reliable method. Nevertheless, Ellis and Throckmorton ${ }^{4}$ argue that in closed treatment, the TMJ is subject to undergoing three types of transformation: regeneration, change in the temporal component of the TMJ and loss of posterior vertical dimension, either capable of returning to being a new sinovial joint or not.

The complications with regard to the treatment of condylar fractures with closed treatment are chronic pain, ${ }^{19}$ greater shortening of the ramus and the face on the affected side (with asymmetry), 5,6,20,27 greater alteration of the occlusal and bigonial planes, ${ }^{20}$ and higher percentage of malocclusions..$^{23,25}$

The TMJ, a ginglymoarthrodial joint, is necessary for the masticatory system to function efficiently and maximally, but it is also unclear whether open treatment would provide a more effective temporomandibular articulation than closed treatment. ${ }^{4}$

Nussbaum et al. (2008) published a critical analysis of the past studies that have directly compared if open or closed treatment of condylar fractures produces the best results. The results were inconclusive regarding whether open or closed treatment should be used for the management of mandibular condylar fractures. Because of the relatively poor quality of the available data and the lack of other important information, the question of preferred treatment still remains unanswered, and there is clearly a need for further research. The authors propose that in future investigations the patients need to be randomized into treatment groups, and the examiners need to be blinded to the manner in which the patients are treated. Similar methods of treatment need to be used. Standardized methods of fracture classification, as well as data collection and reporting, need to be established so that valid comparisons among studies can be made. Studies with adequate sample sizes to determine clinically meaningful effects should be undertaken.

Nevertheless, after reviewing the various articles published over the last few years, it is believed that with exception of absolute indication of closed treat- ment used in children, there are still no rules and/or norms defined for treating condylar fractures. The decision about the choice of the type of treatment must always take into consideration some of the factors, such as the patients' general health status, type of fracture, diagnostic precision, and mainly the capability, experience and skill of the surgeons in this type of lesion.

\section{Acknowledgements}

R. Valiati and R. M. Pagnoncelli are supported by the National Counsel of Technological and Scientific Development (CNPq), Brazil.

\section{Conflict of Interest}

The authors have declared that no conflict of interest exists.

\section{REFERENCES}

1. Mitchell DA. A multicentre audit of unilateral fractures of the mandibular condyle. British Journal of Oral and Maxillofacial 1997; 35: 230-6.

2. Talwar RM, Ellis III E, Throckmorton GS. Adaptations of the masticatory system after bilateral fractures of the mandibular condylar process. J Oral Maxillofac Surg 1998; 56: 430-9.

3. De Riu G, Gamba U, Anghinoni M, Sesenna E. A comparison of open and closed treatment of condylar fractures: a change in philosophy. Int J Oral Maxillofac Surg 2001; 30: 384-9.

4. Ellis III E, Throckmorton GS. Treatment of mandibular condylar process fractures: biological considerations. J Oral Maxillofac Surg 2005; 63: 115-34.

5. Landes CA, Lipphardt R. Prospective evaluation of a pragmatic treatment rationale: open reduction and internal fixation of displaced and dislocated condyle and condylar head fractures and closed reduction of non-displaced, non-dislocated fractures. Part I: condyle and subcondylar fractures. Int J Oral and Maxillofacial Surgery 2005; 34: 859-70.

6. Asprino L, Consani S, De Moraes M. A comparative biomechanical evaluation of mandibular condyle fracture plating techniques. J Oral Maxillofac Surg 2006; 64: 452-6.

7. Alkan A, Metin M, Muglali M, Özden B, Nükhet Ç. Biomechanical comparison of plating techniques for fractures of the mandibular condyle. British Journal of Oral and Maxillofacial Surgery 2007; 45: 145-9.

8. Andersson J, Hallmer F, Eriksson L. Unilateral mandibular condylar fractures: 31-year follow-up of non-surgical treatment. Int J Oral Maxillofac Surg 2007; 36: 310-4.

9. Simsek S, Simsek B, Abubaker AO, Laskin DM. A comparative study of mandibular fractures in the United States and Turkey. Int J Oral and Maxillofacial Surgery 2007; 36: 395-7.

10. Long X, Goss AN. A sheep model of intracapsular condylar fracture. J Oral Maxillofac Surg 2007; 65: 1102-8.

11. Long X, Cheng Y, Li X, Li H, Hu S. Arteriovenous fistula after mandibular condylar fracture. J Oral Maxillofac Surg 2004; 62: 1557-8.

12. Choi J, Rotaru H, Kim IK. Treatment of post-traumatic open bite by radiofrequency. British Journal of Oral and Maxillofacial Surgery 2007; 45: 311-3.

13. Rutges JPHJ, Kruizinga EHW, Rosenberg A, Koole R. Functional results after treatment of fractures of the mandibular condyle. British Journal of Oral and Maxillofacial Surgery 2007; 45: 30-4. 
14. Assael LA. Open versus closed reduction of adult mandibular condyle fractures: an alternative interpretation of the evidence. J Oral Maxillofac Surg 2003; 61:1333-9.

15. Eckelt U, Schneider M, Erasmus F, Gerlach KL, Kuhlisch E, Loukota R, Rasse M, Schubert J, Terheyden $\mathrm{H}$. Open versus closed treatment of fractures of the mandibular condylar process-a prospective randomized multi-centre study. Journal of Cranio-Maxillofacial Surgery 2006; 34: 306-14.

16. Terai $\mathrm{H}$, Shimahara M. Closed treatment of condylar fractures by intermaxillary fixation with thermoforming plates. British Journal of Oral and Maxillofacial Surgery 2004; 42: 61-3.

17. Landes CA, Lipphardt R. Prospective evaluation of a pragmatic treatment rationale: open reduction and internal fixation of displaced and dislocated condyle and condylar head fractures and closed reduction of non-displaced, non-dislocated fractures. Part II: high condylar and condylar fractures. Int J Oral and Maxillofacial Surgery 2006; 35: 115-26.

18. Davis BR, Powell JE, Morrison AD. Free-grafting of mandibular condyle fractures: clinical outcomes in 10 consecutive patients. Int J Oral and Maxillofacial Surgery 2005; 34: 871-6.

19. Haug RH, Assael LA. Outcomes of open versus closed treatment of mandibular subcondylar fractures. J Oral Maxillofac Surg 2001; 59: 370-5.

20. Ellis III E, Throckmorton GS. Facial Symmetry After Closed and Open Treatment of Fractures of the Mandibular Condylar Process. J Oral Maxillofac Surg 2000; 58:719-728.

21. Santler G, Kärcher H, Ruda C, Köle E. Fractures of the condylar process: surgical versus nonsurgical treatment. J Oral Maxillofac Surg 1999; 57: 392-7.

22. Marker $P$, Nielsen A, Lehmann Bastian H. Fractures of the mandibular condyle. Part 2: results of treatment of 348 patients. British Journal of Oral and Maxillofacial Surgery 2000; 38: 422-6.

23. Ellis III E, Throckmorton GS, Palmieri C. Open treatment of condylar process fractures: assessment of adequacy of repositioning and maintenance of stability. J Oral Maxillofac Surg 2000; 58: 27-34.

24. Villarreal PM, Monje F, Junquera LM, Mateo J, Morillo AJ, Gonzalez C. Mandibular condyle fractures: determinants of treatment and outcome. J Oral Maxillofac Surg 2004; 62: 155-163.

25. Ellis III E, Simon P, Thockmorton GS. Occlusal results after open or closed treatment of fractures of the mandibular condylar process. J Oral Maxillofac Surg 2000; 58: 260-8.

26. Zimmermann CE, Troulis MJ, Kaban LB. Pediatric facial fractures: recent advances in prevention, diagnosis and management. Int J Oral and Maxillofacial Surgery 2005; 34: 823-33.

27. Banks P. A pragmatic approach to the management of condylar fractures. Int J Oral Maxillofac Surg 1998; 27: 244-6.

28. Choi J, Oh N, Kim IK. A follow-up study of condyle fracture in children. Int J Oral Maxillofac Surg 2005; 34: 851-8.

29. Tominaga K, Habu M, Khanal A, Mimori Y, Yoshioka I, Fukuda J. Biomechanical evaluation of different types of rigid internal fixation techniques for subcondylar fractures. J Oral Maxillofac Surg 2006; 64: 1510-16.

30. Brandt MT, Haug RH. Open versus closed reduction of adult mandibular condyle fractures: a review of the literature regarding the evolution of current thoughts on management. J Oral Maxillofac Surg 2003; 61: 1324-32.

31. Anastassov GE, Lee H, Schneider R. Arthroscopic reduction of a high condylar process fracture: a case report. J Oral Maxillofac Surg 2000; 58: 1048-51.

32. Wagner A, Krach W, Schicho K, Undt G, Ploder O, Ewers R. A 3-dimensional finite-element analysis investigating the biomechanical behavior of the mandible and plate osteosynthesis in cases of fractures of the condylar process. Oral Surg Oral Med Oral Pathol Oral Radiol Endod 2002; 94: 678-86.
33. Hlawitschka M, Eckelt U. Assessment of patients treated for intracapsular fractures of the mandibular condyle by closed techniques. J Oral Maxillofac Surg 2002; 60: 784-91.

34. Nussbaum ML, Laskin DM, Best AM. Closed Versus Open Reduction of Mandibular Condylar Fractures in Adults: A Meta-Analysis. J Oral Maxillofac Surg 2008; 66:1087-1092. 